\title{
Consumer mobility and the relative importance of consumption and competition following physical disturbance
}

\author{
Denise L. Breitburg* \\ The Academy of Natural Sciences, Benedict Estuarine Research Center, 10545 Mackall Rd, St. Leonard, Maryland 20685, USA
}

\begin{abstract}
Simple models and an example from the published literature suggest how consumer mobility can alter the relative importance to producers of consumption (predation and herbivory) and competition following a disturbance that opens habitat for colonization. Highly mobile consumer species often can colonize disturbed habitat at juvenile and adult life stages with high per capita consumption rates. In contrast, consumers with limited mobility, as well as sessile or sedentary prey, can be restricted to colonization of disturbed habitat by reproductive propagules, and initially have low per capita consumption, and low biomass and per capita production, respectively. Following a disturbance, the relationship between potential consumption and production can differ in important ways from that prior to the disturbance if consumer and prey species differ markedly in mobility, but may be similar to that prior to the disturbance if consumers and prey are both limited to colonization by reproductive propagules. Functional responses of consumers, and growth rates of consumers relative to producers, can determine how strongly consumer mobility will influence post-disturbance interactions. In California (USA) kelp forests, sea urchins may be able to colonize disturbed patches as adults or can be restricted to colonization by larval settlement depending on habitat characteristics and how their foraging behavior affects sea urchin susceptibility to winter storms. On Naples Reef, near Santa Barbara, California, recovery of macroalgae including giant kelp was inhibited under grazing by adult urchins but was rapid when sea urchins colonized through larval settlement.
\end{abstract}

KEY WORDS: Competition · Consumers · Kelp bed · Mobility - Model · Physical disturbance · Predation Sea urchin

\section{INTRODUCTION}

Physical disturbance, competition and trophic interactions potentially influence community structure. However, the relative importance of these factors varies in space and time (Sousa 1984, Sih et al. 1985, Menge \& Sutherland 1987). Where disturbance is infrequent or episodic, the abundance and presence of species may be largely determined by colonization and biotic interactions that occur as the assemblage colonizes and regrows between disturbances (Connell 1978, Sousa 1984, Petraitis et al. 1989).

In this paper I use simple models and an example from the marine literature to explore how a difference

•E-mail: breit@acnatsci.org between consumer (predators or herbivores) and producer mobility can influence the relative importance of consumption and competition as the assemblage within a disturbed patch increases in biomass following a physical disturbance that creates open space. The key feature of consumer mobility examined is the relationship between adult mobility and the lifehistory stages during which consumers can colonize disturbed habitat. Although the potential importance of consumer mobility to the persistence of predator and prey populations has been recognized at least since Huffaker (1958) and is an important feature of recent models (e.g. Taylor 1990, McLaughlin \& Roughgarden 1993, Walde 1994), the importance of consumer mobility per se has generally not been stressed in the large body of theoretical and empirical studies that focus on physical disturbance (Breitburg \& Loher 1994; also see 
reviews in Karr \& Freemark 1985, and Schowalter 1985; see Frid \& Townsend 1989 for examples of exceptions). Disturbance as examined here is important not only because it creates open space for substrate-occupying species to colonize, but because it can influence which life stages of consumers and producers interact.

'Adult' mobility constrains the life stage at which both producers and consumers can colonize disturbed habitat (in this paper, the term 'adult' will include juveniles that are near a species' typical adult size as well as reproductively malure individuals). Where a disturbance affects large or isolated habitat patches, colonization by sessile prey, including plants and sessile animals, is primarily through small reproductive products (e.g. spores, seeds or larvae) and vegetative fragments (Oliver \& Stephens 1977. Paine \& Levin 1981, Keough 1984, Connell \& Keough 1985). As a result of small colonist size, both producer standing biomass (by definition), and production expressed on a per individual (not per unit biomass) basis are initially low. Competition among producers for space and other resources should generally be less important immediately following colonization than it is after somatic growth or asexual reproduction (e.g. budding) have occurred. Consumers whose mobility is severely limited because of ecological constraints (e.g. physical barriers to adult movement; reviewed in Sebens 1991) and/or inherent biological characteristics will likewise be restricted to colonizing mostly by reproductive propagules. Because of their small size, per capita consumption (e.g. g C ind..$^{-1} \mathrm{~d}^{-1}$ ) of these colonists will initially be low. Within species, per capita consumption rates of both fish (Wooton 1990) and invertebrates (Sebens 1987) generally increase with increasing body size.

In contrast to sessile prey and consumers with severely limited mobility, highly mobile consumers can often colonize during more than one life-history stage (Frid \& Townsend 1989, Breitburg \& Loher 1994). In marine environments, most highly mobile consumers can colonize by larval settlement as well as by immigration of juveniles and adults from surrounding undisturbed habitat and from refuges where they survived the disturbance. Because of the larger size at which some of these migrants potentially reach the disturbed habitat, per capita consumption rates during the period shortly following colonization should generally be higher than that for consumers colonizing as larvae. Where mobile consumers can colonize as adults or large juveniles, therefore, potential net consumption following a disturbance may not decrease as substantially as does net production by sessile prey per unit area of habitat. The consequences of these changes in consumption relative to production and producer bio- mass are explored below in models and in a re-examination of a series of studies of the relationships among sea urchins Strongylocentrotus franciscanus and $S$. purpuratus, macroalgae including giant kelp Macrocystis pyrifera, and severe winter storms (Ebeling et al. 1985, Laur 1990).

\section{MODEL}

Production and consumption functions were compared graphically and through numerical simulations to specifically consider 2 questions. First, how does consumer colonization at life stages that initially have high versus low per capita consumption affect equilibrium prey biomass under a variety of consumer functional responses and growth rates? Equilibria considered here were stable and unstable points at which consumption equaled net production of the prey (producer) assemblage. Second, how does consumer colonization at life stages with initial high versus low per capita consumption affect the relative importance of consumption and competition among producers as both producer and consumer assemblages regrow following a physical disturbance? In this paper I examine only the simple case in which: (1) consumers initially colonize a patch at either extremely low per capita consumption rates (simulating larval settlement) or at the species-specific maximum consumption rate (simulating colonization by migrating adults or late-stage juveniles); (2) all colonization occurs at a single point in time following a disturbance that completely clears a

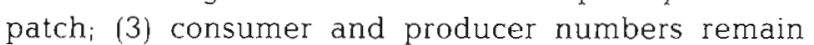
constant following the initial colonization event; and (4) all producers are competitive equivalents such that the intensity of competition is reflected in a single measure of net production. These models are designed to illustrate a simple but important step in exploring how consumer mobility affects post-disturbance community dynamics.

The approach of graphical comparisons of consumption curves and producer growth curves (Fig. 1) closely follows that of Noy-Meir (1975) and has been used extensively in both older (originating with Rosenzweig \& MacArthur 1963) and more recent (e.g. Knowlton 1992) papers. The models described below are, therefore, not intended to introduce new predator-prey theory, but instead apply an established approach to a different problem - the relationship between consumer mobility and recovery of a prey assemblage following a disturbance. Assumptions of these deterministic predator-prey models are discussed in detail in Noy-Meir (1975). The models are most appropriate for prey such as plants and colonial invertebrates whose biomass can be reduced by predators without suffering 

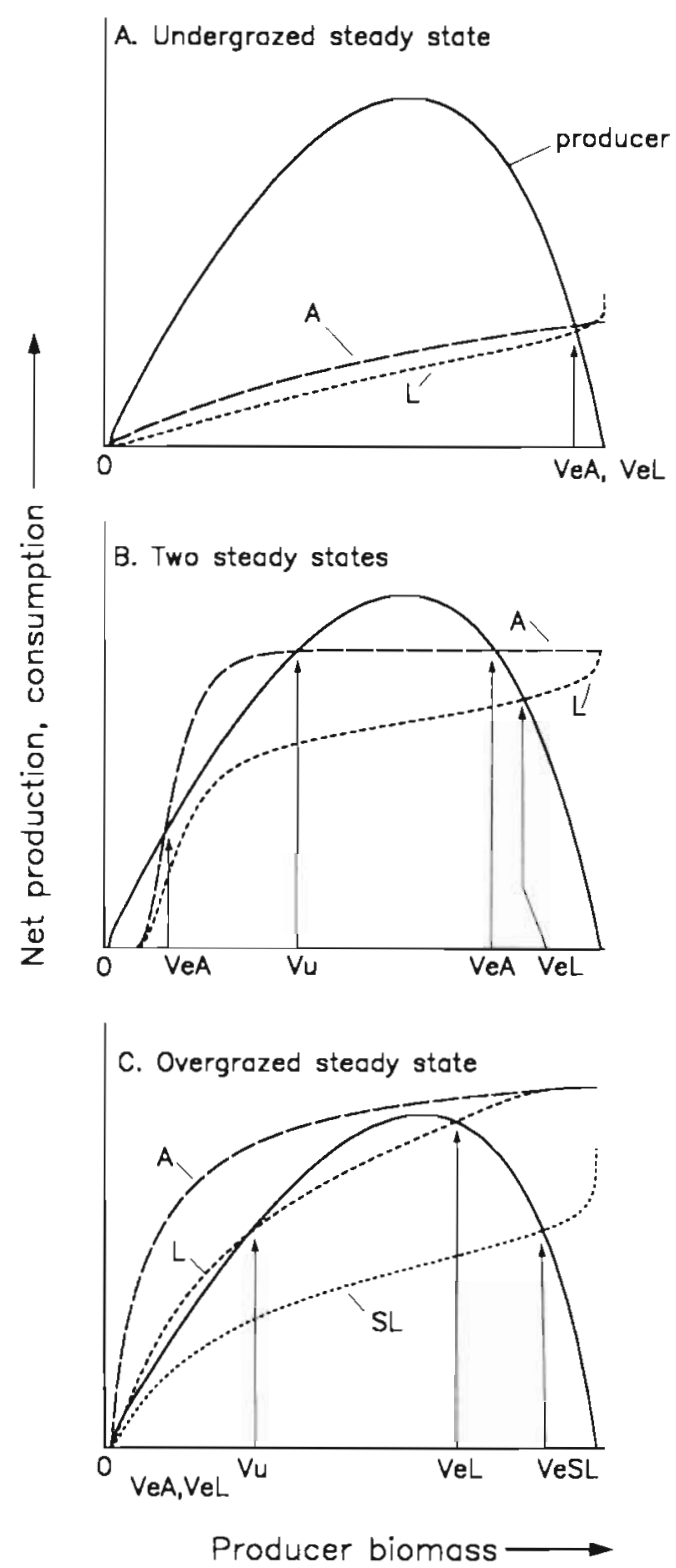

Fig. 1. Consumption and net production as functions of the biomass of producers. The use of different functional response curves and parameter values produced (A) undergrazed steady state, (B) two steady-state, and (C) overgrazed to low biomass steady state models. (-) production; (- - A) consumption by adults; (-.-.-, L) consumption when colonization is by larvae of consumers that reach maximum consumption rates in approximately the same amount of time required for ungrazed producers to reach maximum biomass; (........, SL) consumption when colonization is by larvae of a slow-growing consumer. VeA, VeL, and VeSL designate stable equilibrium points with adult and larval consumer colonization, respectively. Vu: unstable equilibrium point. The upswings in larval colonizer consumption at points approaching maximum producer biomass occur because continued consumer growth causes consumption to increase proportionately faster than producer biomass as production approaches zero, i.e. a wide range of consumption rates are possible for a narrow range of producer biomass mortality. However, the conceptual arguments should apply to other prey as well. Because the range of qualitatively different outcomes, and the general shapes of consumption and producer growth curves, are of primary concern here, I focus on a graphical presentation of the model results. Equations and parameter values are detailed in Appendix 1. Specific equilibria are highly sensitive to parameter values chosen. However, consumer and producer curves with the general shapes and characteristics illustrated can be generated using many combinations of values for the relevant parameters.

Consider first producer colonization of a large cleared patch free of consumers. These substrate-occupying species may be either primary producers (e.g. benthic macroalgae) or secondary producers (e.g. sessile epifauna). Producer colonization is by spores, seeds or larvae. The net production curves in Fig. 1 describe the relationship between production and producer biomass in the absence of consumers. The increasing producer biomass along the horizontal axis can also be thought of as representing colonization and regrowth of the producer assemblage following a disturbance. In the absence of consumers, net production increases early during colonization, and then decreases as resources (e.g. space, light) are monopolized. The descending portions of the producer growth curves represent levels of producer biomass at which competition (e.g. substrate or light limitation) among producers is important; at high producer biomass competition reduces net production. In terms of the sequence of events during regrowth of the prey assemblage, maximum net production occurs at an earlier point in time following the disturbance than does maximum producer biomass.

Consumer population functional responses (the total prey biomass removed by the consumer population as a function of prey biomass) are then superimposed on the producer growth curves (Fig. 1). Ranges of prey biomass over which consumption exceeds production define those parameter values where consumers reduce the biomass of producers. Where consumption is lower than production, consumers affect the rate of increase of producer biomass but do not reduce standing producer biomass. Points at which consumption equals production, and the consumption and production curves intersect, represent either stable or unstable equilibria. The unstable equilibria divide regions where producer populations will increase or decrease towards alternate stable points. Simulations were used to verify stability (trend towards a constant prey biomass) of equilibria.

Numerical simulations were also used to link the production and functional response equations shown in the graphical models in order to examine consumer 
biomass that results when consumers remove producer biomass during each time step, and to incorporate consumer growth in simulations of larval settlement of consumers. In these simulations, a fixed number of producer and consumer colonists arrive simultaneously at some point in time following a disturbance. Producer biomass is influenced both by processes intrinsic to the producer population [determined by parameter values for initial prey biomass $\left(V_{0}\right)$, intrinsic rate of increase in prey biomass $(r)$, and carrying capacity $(K)$ in Appendix Table 1 ], and the consumer functional response. However, consumer growth rates are independent of producer biomass or production rates as could occur if an external source of less preferred prey, or alternative feeding habitat, were available. The numerous marine examples of both herbivorous fish and invertebrates maintaining prey patches in a low-biomass state indicate that mobile consumers do not always abandon 'overgrazed' patches, but instead may maintain sufficient pressure to strongly influence regrowth of prey populations (Lawrence 1975, Horn 1989, Hay 1991).

\section{Colonization by adult consumers}

Now consider 3 cases of colonization by a population of consumers of sessile prey. These cases were selected because they vary in the importance of consumption relative to competition, and in the number and location of stable equilibria. The functional response equations and parameters used to generate each case are listed in Appendix 1 and Appendix Table 1, and were selected to illustrate general consumption-production relationships that roughly correspond to the 'undergrazed steady-state', 'two steady-state', and 'overgrazed to low biomass steady-state' models in NoyMeir (1975). I therefore use his terminology to describe the model properties. First I review the general properties of each consumer case as described by Noy-Meir (1975) and then discuss the implications of these cases for colonization by adult consumers following a disturbance. Next, the consequences of colonization by larval consumers are examined and compared with adult consumer colonization.

In the 'undergrazed steady-state model', net production is greater than consumption by adults at all but the highest levels of producer biomass (Fig. 1A). Thus, processes within the producer assemblage (e.g. competition and maximum potential growth rates), rather than producer-consumer interactions, are of primary importance to determining the rate of increase in producer biomass at all but the highest levels of producer biomass. A single stable equilibrium point occurs at high producer biomass when competition and/or resource depletion have already reduced production below maximum levels (Figs. 1A \& 2A). Regrowth of the assemblage is least affected by consumers in the undergrazed model. No refuge from consumers exists in this model.

In the 'two steady-state model', the relative importance of competition and consumers varies with pro-

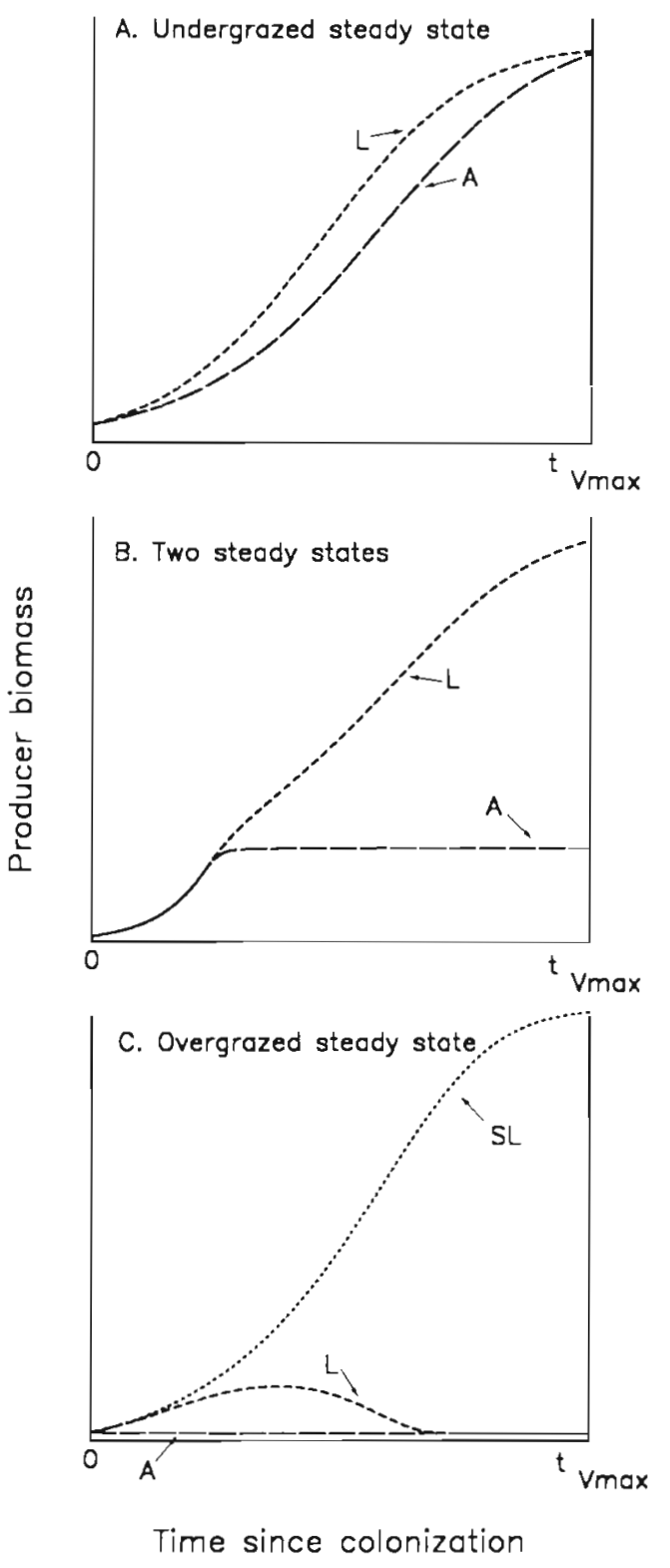

Fig. 2. Producer biomass as a function of consumer functional response and time since colonization in interactive simulations. Adult functional response curves are the same as those plotted in Fig. 1. (- - A) producer biomass with colonization by adult consumers; (-----, L) producer biomass with colonization by larval consumers; and (-......., SL) producer biomass with colonization by larvae of slow-growing consumers. $t_{V \max }$ : time to maximum producer biomass in the absence of consumers 
ducer biomass (Fig. 1B). A feature of this model is that a constant prey biomass is retained unavailable to consumers representing a physical refuge. Consumption rises quickly in response to increasing producer biomass, but satiates at levels such that maximum consumption is less than maximum net production. Thus, consumers potentially reduce producer biomass at moderate and extremely high levels of producer biomass, but not when the only remaining biomass is that reserved in the refuge or corresponds to peak production rates. Two stable equilibria - one at high and one at low producer biomass - and one unstable equilibrium at an intermediate biomass occur.

When the time sequence following disturbance is considered, colonization by adults results in an equilibrium only at low producer biomass in this model (Fig. 2B). The equilibrium point indicated by the intersection of production and functional response curves at high producer biomass in Fig. 1B is not reached during regrowth of the assemblage following disturbance. The producer population does not increase at population levels at which consumption exceeds production, and therefore cannot reach the biomass of the second potential equilibrium point.

The final case, the 'overgrazed to low biomass steady-state model', also sets a lower limit to producer biomass representing a quantity unavailable to consumers. Here, consumption exceeds net production at all producer biomass levels except the very low quantity of producer biomass that is retained unavailable to grazers (Fig. 1C). A single stable equilibrium occurs at low producer biomass (Figs. $1 \mathrm{C} \& 2 \mathrm{C}$ ), and competition among producers does not limit production at any level of producer abundance as the assemblage regrows.

\section{Colonization by larval vs adult consumers}

To consider how the same 3 cases would be altered if consumers had limited mobility as adults and were restricted to colonizing by larval settlement, I made consumption proportional to the size of consumers and included the temporal sequence of consumer growth following a disturbance. The primary effect of larval colonization incorporated in these models, therefore, is a lowering of consumption rates during the initial time periods following the colonization event. The consumer in these models is patterned after the purple sea urchin Strongylocentrotus purpuratus. The ability of sea urchins in the genus Strongylocentrotus to overgraze or control producer populations has been documented for rocky subtidal habitats along both the east and west coasts of North America (e.g. Paine \& Vadas 1969, Mann 1982, Ebeling et al. 1985).
Consumer growth following larval colonization in both the functional response curves (Fig. 1) and simulations (Fig. 2) is calculated by fitting a modified Von Bertalanfy growth function to empirical data on sea urchin Strongylocentrotus purpuratus log growth rates (Appendix Table 2):

$$
\log D_{t}=2.1[1-\exp (-0.11 t)]
$$

where $D_{t}=$ urchin test diameter at time $t$. For the models I make the assumption that sea urchin consumption rates (biomass consumed per individual per unit time) are proportional to the log of sea urchin test diameter. All individuals in the population colonize at the same time and grow at the same rate. Therefore, consumption rate of the consumer population is directly proportional to the consumption of an individual during development. Although the parameters I use here to model consumer growth are based on a single species, the general shape of the growth curve generated, and therefore the relationship between ontogenetic development and consumption rates, should be common. For purposes of illustration, I scale consumer growth in 2 ways: (1) so that the time course to peak producer biomass and peak consumption are similar; and (2) with time to peak producer biomass faster $(6 \times)$ than the time to peak consumption. Calculations of population consumption rates are described in Appendix 1. As with adult colonization, consumer population size is held constant.

The difference in predicted producer-consumer dynamics between larval and adult colonization varied among the 3 adult functional responses modeled (compare curves ' $L$ ' vs ' $A$ ' in Figs. 1 \& 2) A lowering of initial consumption rates has its strongest effect (e.g. the greatest difference between adult and larval colonization) where adults have high consumption rates during the time period soon after colonization because of high potential per capita consumption at low levels of consumer biomass.

The undergrazed steady state models show only minor differences between adult and larval colonization (Figs. 1A \& 2A). Consumption by adults does not exceed production until high producer biomass is reached and a lowering of initial consumption rates with larval colonization does not change this general relationship. Thus, with larval colonization, the equilibrium point is delayed only slightly with respect to time since colonization and approach to maximum producer biomass. The equilibrium producer biomasses are similar and both adult and larval colonization yield a single stable equilibrium point. The relative importance of competition and consumption as the prey assemblage regrows following a disturbance changes little. 
In contrast, limiting consumers to larval colonization can fundamentally alter: (1) the range of producer biomasses over which consumption exceeds production; (2) the importance of competition within the producer population; and (3) the number of potential stable equilibria in both the two steady-state (Figs. 1B \& 2B) and overgrazed steady-state (Figs. 1C \& 2C) models. In these models, low early consumption rates of larval colonists result in a shift of one or more points at which consumption exceeds production from low producer biomass, where competition is unimportant, to high producer biomass, where competition within the producer population limits production.

Larval colonization can shift the two steady-state model to one with a single stable equilibrium at high producer biomass, i.e. to an undergrazed model (Figs. 1B \& 2B). With larval colonization, consumption exceeds production only when density-dependent processes within the producer population would already limit production. Eliminating the ability of consumers to colonize as adults thus increases equilibrium prey biomass and the relative importance of competition among producers.

Similarly, larval colonization with similar consumer growth:producer growth can shift the overgrazed to low producer biomass model to a two steady-state system (Figs. $1 C \& 2 C$ ). Because only the lower producer biomass stable equilibrium would be reached during regrowth of the assemblage following a disturbance and colonization by larval consumers, however, adult and rapidly growing larval consumer colonists result in the same stable equilibrium producer density. That density is achieved at a later time following the disturbance with larval colonization than with adult colonization.

In contrast, the number and location of equilibrium points in the overgrazed to low biomass model are altered by slowing growth rates of larval colonists (curve 'SL' in Figs $1 \mathrm{C} \& 2 \mathrm{C}$ ). Thus there is an interaction between consumer functional response and the growth rate of consumers relative to producers that can contribute markedly to the way in which consumer mobility and colonization mode affect the balance between consumption and production following a disturbance that clears space. When the consumer growth rate (time to peak consumption) was considerably slower than producer growth rate (time to maximum biomass), the adult functional response that yielded overgrazing at most levels of producer biomass yielded an undergrazed steady state under Iarval colonization. The relative importance of competition among producers and of consumption was altered during much of the time course between initial colonization and the attainment of maximum producer biomass, and equilibrium producer biomass increased.

\section{A MARINE EXAMPLE}

An example that may illustrate the importance of the relationship between consumer mobility and the lifehistory stage at which consumers colonize affected habitat following a disturbance is described in several studies conducted on Naples Reef, a subtidal rocky reef near Santa Barbara, California (summarized in Ebeling et al. 1985 and Laur 1990). Prior to a series of storms in the early 1980 s the reef was characterized by thick growths of giant kelp Macrocystis pyrifera as well as understory fleshy macroalgae. Sea urchins Strongylocentrotus purpuratus and $S$. franciscanus were abundant, but apparently did not overgraze the upper part of the reef: coralline algae-dominated urchin barrens were restricted to deep reef margins (ca 15 to $18 \mathrm{~m}$ ) where light may have limited production of kelp and other uncalcified erect macroalgae. I know of no specific descriptions of the shape of the functional response curves of sea urchins. However, the persistence of urchin barrens suggests that at low producer biomass sea urchins are capable of consuming most production except perhaps holdfasts in crevices and coralline algae crusts. On the other hand, the existence of dense kelp beds suggests that at typical urchin densities, net production (including detrital drift) exceeds or at least equals the grazing on algal standing stock for a range of producer biomasses. In either case, sea urchins likely consume a non-trivial fraction of production. Thus the relationship between sea urchins and algae may be most similar to that illustrated in Fig. 1B; the low biomass stable equilibrium would represent the urchin barrens condition while the high biomass stable equilibrium point would represent the kelp-dominated situation. The ability of sea urchins to withstand long periods of starvation (Ebert 1967, Lang \& Mann 1976), and consume drift algae (Vadas 1977, Harrold \& Reed 1985) limits the effect of within-patch production on urchin density. Therefore, as in the models, potential consumption is not strongly dependant on prey biomass or production within the disturbed patch.

In 1980, a severe winter storm denuded most of the reef of giant kelp and other erect macroalgae (Ebeling et al. 1985). Although some urchin mortality undoubtedly occurred, many sea urchins survived in crevices and other refuges, and reef-wide densities were likely little affected by the storm (Laur 1990). These surviving 'adults' recolonized the upper portions of the reef, and maintained the formerly lush reef in an overgrazed state dominated by crustose algae. Kelps recruited onto newly exposed rock substrate but were removed by grazing before they exceeded a few $\mathrm{cm}$ in length (Breitburg unpubl. data). Thus, following the disturbance, exposed areas of the reef were colonized 
by adult sea urchins, but colonization by macroalgae was restricted to reproductive propagules. With this difference in life-history stage of colonizing consumers and producers, consumers were able to remove macroalgae and maintain Naples Reef in a low biomass state.

Three years after the initial disturbance, a second disturbance required that sea urchins as well as their macroalgal prey colonize the disturbed habitat through reproductive propagules. Because of a change in the behavior of sea urchins to more exposed habitat under low producer biomass conditions, the second severe storm killed most of the adult urchins on the reef (Ebeling et al. 1985). Colonization by adult sea urchins from surrounding areas was impeded by the large stretches of sand surrounding Naples Reef. Strongylocentrotus purpuratus and $S$. franciscanus are highly mobile on hard substrate but have limited mobility across open sand (Ebeling et al. 1985, Laur 1990). Sea urchins recruited in extremely high numbers (Rowley 1990), and it is likely that densities following the second storm were similar to or exceeded pre-disturbance and between-disturbance densities. However, newly settled sea urchins have test diameters $\leq 1 \mathrm{~mm}$ (Rowley 1990), and the potential mean per capita consumption rate of these new recruits was undoubtably much lower than that of the former mixed age-structure population that included many adults. Both overstory giant kelp and understory macroalgae rapidly recovered to biomasses resembling those prior to the first storm. As illustrated in Fig. 1B (curve L) production exceeded consumption for a substantial time (relative to algal growth rates) following colonization, potentially allowing competition among algae (e.g. shading by the algal canopy) to limit producer growth rates of understory macroalgae (Foster 1975). In sum, the life-history stage at which the dominant grazer colonized following the disturbance likely determined the importance of consumption to post-disturbance community development. Limitations to consumer mobility enabled these alternate modes of colonization to occur. The example also points out how characteristics of mobility that can determine whether consumers colonize at high or low per capita consumption rates can be habitat and scale dependent, not simply a speciesspecific characteristic.

Of course, the dynamics of natural kelp bed systems are far more complex than those described in simple deterministic models, and there are important differences between newly settled recruit and adult feeding behaviors in addition to biomass consumed. Extremely small urchin recruits feed on algal crusts (Rowley 1990), and the feeding behavior of adult sea urchins can result in a greater biomass of macroalgae being removed from the substrate than is actually consumed (Bernstein et al. 1981). A time delay between coloniza- tion by larval settlement and the switch to adult prey may be common and would in fact accentuate the difference in effects of adult and larval colonization. Alternatively, if small, newly settled consumers preferentially forage on new recruits of their prey, the effect on prey populations can be greater than that attributed to biomass removal (Osman et al. 1992). Nevertheless, I suggest that in the Naples Reef example, the limited ability of sea urchins to colonize isolated habitat patches as adults is the key feature that allowed recovery of the kelp bed to take place (Ebeling et al. 1985. Laur 1990).

\section{DISCUSSION}

Because marine consumers vary widely in both adult mobility and the life stage at which they typically colonize disturbed habitat, a consideration of consumer mobility is important to an understanding of the effects of disturbance in marine systems (see also Menge \& Sutherland 1987). The above model and example illustrate how consumer mobility can alter the relative importance of consumption and competition following a disturbance because of the relationship between adult mobility and the life-history stage at which consumers colonize disturbed habitat. The importance of consumption relative to competition among producers should increase with increasing mobility of adult consumers. Furthermore, change in the importance of consumption relative to competition should vary with the consumer functional response and growth rate. Similar proportional changes in size-specific consumption rates can more fundamentally alter consumption:production relationships with certain forms of functional responses than with others. In addition, the relationship between the time it takes for consumers to grow to their size of maximum consumption, and for producers to reach maximum production and biomass, can determine how a particular functional response curve will be altered.

Three conditions are likely to lead to high dependence of post-disturbance community dynamics on the adult mobility of colonizing consumers: (1) greater mobility of consumers than their prey; (2) the ability of consumers to limit the density or biomass of prey populations; and ( 3 ) the ability of consumers to colonize habitat during the life stage with highest per capita consumption. The first condition is likely to be generally met in a wide variety of both aquatic and terrestrial systems. With important exceptions such as sessile filter feeders and some ambush predators, consumers are generally more mobile (faster, wider ranging) than their prey. This mobility should enable adult consumers to sometimes escape a disturbance and then 
return to their original home range, or else to immigrate into the disturbed patch from surrounding undisturbed habitat. The effect of consumer mobility will be most profound where the producer population is truly sessile, and thus limited to colonization by early lifehistory stages. Examples of such producers include marine macroalgae and sessile marine invertebrates, as well as terrestrial plants.

The second condition, the ability of consumption to exceed net production at some ranges of producer density or biomass, has also been recorded for both aquatic and terrestrial systems. Marine examples of overgrazed systems include sea urchins in subtidal kelp beds and halos created around coral reefs by herbivorous fishes. In addition, coral reefs may present a situation analogous to the sea urchin example presented above. Predation on recruits and surviving coral fragments by snails and damselfish has been suggested as one mechanism contributing to the maintenance of Jamaican reefs in a state of low coral cover, and slowing the return of the community to the high coral cover that existed prior to hurricane Allen (Knowlton et al. 1990, Knowlton 1992). In terrestrial systems, some insects and mammals are attracted to disturbed patches where herbivore populations reach levels at which plant biomass can be reduced by grazing (Sousa 1984, Schowalter 1985). Furthermore, wild populations of large mammalian grazers have historically limited woody plant biomass in grasslands and savannahs (Wiens 1985). However, only in a subset of aquatic and terrestrial systems in which consumption sometimes exceeds net production will the relationship between consumer functional response, and consumer and producer growth rates, be such that larval and adult colonization yield qualitatively different effects on producer populations.

The third condition, the ability of consumers to colonize at sizes/ages with near-peak consumption rates, should make the role of consumer mobility readily apparent in aquatic systems, but important to terrestrial systems as well. Most marine animals have dispersive larvae. Thus for marine systems, colonization may be by either these early life-history stages or by adults, depending on the timing, spatial scale and severity of the disturbance. In marine systems it should therefore be possible to detect the contrasting effects of larval and adult colonization by consumers. In contrast, in terrestrial systems older life-history stages are generally most mobile. Therefore initial colonization by consumers will largely be by adults or late-stage juveniles, not by larvae (for insects) or newborns (for mammals).

The relative importance of physical disturbance and biotic interactions has been a major theme in population and community ecology (e.g. reviews in Pickett \&
White 1985, Menge \& Farrell 1989). The models presented here, as well as several recent papers (Frid \& Townsend 1989, Breitburg 1992, Breitburg \& Loher 1994) suggest that more attention needs to be focussed on the relationship between consumer mobility and the effects of physical disturbance in communities. Extensions of the current models, which could include mortality of consumers during development, the dependence of consumer growth on production, colonization over extended periods of time, as well as dynamics in a multi-patch system, should produce further insight on the problem.

Acknowledgements. This work was funded by the Supported Research Fund of the Academy of Natural Sciences and NSF grant OCE-9102641. I thank J. Bence, P. Petraitis, R. Osman, M. Palmer, K. Sebens, R. Whitlatch and S. Gaines for helpful suggestions on earlier drafts of this manuscript and discussions of the ideas presented here.

\section{LITERATURE CITED}

Bernstein BB, Williams BE, Mann KH (1981) The role of behavioral responses to predators in modifying urchins' (Strongylocentrotus droebachiensis) destructive grazing and seasonal foraging patterns. Mar Biol 63:39-49

Breitburg DL (1992) Episodic hypoxia in the Chesapeake Bay: interacting effects of recruitment, behavior and physical disturbance. Ecol Mongr 62:525-546

Breitburg DL, Loher T (1.994) Effects of physical disturbance on fish trophic interactions: the importance of consumer mobility. In: Stouder DJ, Fresh K, Feller RJ (eds) Feeding ecology of fishes: theory and application. Belle Baruch Library in Marine Science, University of South Carolina Press, Columbia, p 241-254

Caughley G (1976) Plant-herbivore systems. In: May RM (ed) Theoretical ecology: principles and applications. WB Saunders Co, Philadelphia, p 94-113

Connell JH (1978) Diversity in tropical rain forests and coral reefs. Science 199:1302-1310

Connell JH, Keough MJ (1985) Disturbance and patch dynamics of subtidal marine animals on hard substrata In: Pickett STA, White PS (eds) The ecology of natural disturbance and patch dynamics. Academic Press, Orlando, p $125-151$

Ebeling AW, Laur DR, Rowley RJ (1985) Severe storm disturbances and reversal of community structure in a southern California kelp forest. Mar Biol 84:287-294.

Ebert TA (1967) Negative growth and longevity in the purple sea urchin Strongylocentrotus purpuratus. Science 157 $557-558$

Ebert TA (1977) An experimental analysis of sea urchin dynamics and community interactions on a rock jetty. J Exp Mar Biol Ecol 27:1-22

Fnd CLJ, Townsend CR (1989) An appraisal of the patch dynamics concept in stream and marine benthic communities whose members are highly mobile. Oikos 56 $137-141$

Foster MS (1975) Regulation of algal community development in a Macrocystis pyrifera forest. Mar Biol 32:331-342

Harrold C, Reed DC (1985) Food availability, sea urchin grazing, and kelp forest community structure. Ecology 66 : $1160-1169$ 
Appendix 1. Relationship between consumer mobility and recovery of a prey assemblage following a disturbance. Equations and parameter values

The increase in producer biomass within the patch undergoing colonization was modeled with the discrete analog of logistic growth, which is a reasonably good descriptor of a generalized plant growth curve (Caughley 1976):

$$
V_{t+1}=V_{t} \exp \left[r\left(1-V_{t} / K\right)\right]
$$

where $V$ is the biomass of vegetation (or sessile fauna) per unit area, $t$ is time, $r$ is the per capita rate of increase in biomass, and $K$ is the maximum quantity of vegetation or sessile epifauna that can be sustained within the patch. Net production $(P)$ was defined as the change in producer biomass per unit time in the absence of consumers $\left(P_{t+1}=\right.$ $\left.V_{t+1}-V_{t}\right)$

The quantity of producer biomass consumed by colonizing adult consumers was determined by their functional responses to prey abundance. Two alternate equations were used in order to generate the desired qualitative shapes of population functional responses $\left(C_{a}\right.$ and $\left.C_{b}\right)$ of adult consumers:

and

$$
C_{a}=C_{\max } H[V /(V+A)]-R
$$

$$
C_{\mathrm{b}}=C_{\max } H\left\{1-\exp \left[-\mathrm{a}\left(V-R_{1}\right)\right]\right\}-R_{2}
$$

where $c_{\max }$ is the maximum per capita consumption rate, $H$ is the size of the consumer (predator or herbivore) population, $A$ is the producer abundance beyond which consumption rapidly saturates, and $a$ is the search efficiency of the consumer (Ivlev 1961, Holling 1966). Both functions allow for consumer satiation at high producer biomass (i.e high $V$ ) and the subtraction of a constant biomass unavailable to consumers during each time unit ( $R$ or $R_{1}$ and $R_{2}$ ).

At each step in time in the interactive simulation models, biomass consumed is subtracted from producer standing stock plus production such that

$$
V_{l+1}=V_{l}+P_{l}-O_{l}
$$

where $O_{1}$ is the population consumption at time $t$ during ontogeny of a uniformly aged consumer population. For adult colonization, $O_{t}=C_{a}$ or $C_{b}$ (the adult population functional response) at time $t$. For larval colonization, population consumption rates at time $t$ during ontogeny were calculated as

$$
O_{t}=C\left(D_{t} / D_{\text {max }}\right)
$$

where $C=C_{a}$ or $C_{b}$ (the adult population functional response), and $D_{\max }$ is the consumer size at which maximum consumption rates are reached. For colonization by adults, $D_{t}=D_{\max }$ for larval colonization, $D_{t} \leq D_{\max }$.

Appendix Table 1. Parameter values used for producer growth and consumer functional response models. Model outcomes were sensitive to parameter values. Values selected for inclusion in this paper were chosen to illustrate the range of qualitatively different outcomes of larval and adult colonization

\begin{tabular}{|lccccccc|}
\hline $\begin{array}{l}\text { Model } \\
\text { (adult form) }\end{array}$ & $V_{0}$ & $r$ & $K$ & $\begin{array}{c}\text { Functional } \\
\text { response }\end{array}$ & $C_{\text {max }} \cdot H$ & $\begin{array}{c}A \\
\text { or a }\end{array}$ & $\begin{array}{c}R \text { or } \\
R_{1}, R_{2}\end{array}$ \\
\hline Undergrazed steady-state & 1 & 0.5 & 100 & $C_{\mathrm{a}}$ & 10 & 100 & 0 \\
Two steady-state & 1 & 0.6 & 250 & $C_{\mathrm{b}}$ & 15 & 0.2 & 12,2 \\
Overgrazed steady-state & 1 & 0.72 & 110 & $C_{\mathrm{a}}$ & 18.5 & 5 \\
\hline
\end{tabular}

Appendix Table 2. Growth rates of the purple sea urchins Strongylocentrotus purpuratus used for calculations in models. Data are from studies cited in Rowley (1990, Table 1) for sea urchins fed on macroalgae (other diets excluded). Original sources of data are listed under comments

\begin{tabular}{|ccl|}
\hline $\begin{array}{c}\text { Test diameter } \\
(\mathrm{mm})\end{array}$ & $\begin{array}{c}\text { Growth rate } \\
\left(\mathrm{mm} \mathrm{mo}^{-1}\right)\end{array}$ & Comments \\
\hline $0.5-1$ & 0.30 & Rowley (1990) \\
$1-2$ & 0.90 & Rowley (1990) \\
$2-10$ & 1.64 & Rowley (1990) \\
$10-60$ & 2.03 & Mean of Pearse et al. (1986), Pearse et al. (1970), and maximum value \\
& & listed for Ebert (1977) \\
\end{tabular}

Hay ME (1991) Fish-seaweed interactions on coral reefs: effects of herbivorous fishes and adaptations of their prey. In: Sale PF (ed) The ecology of fishes on coral reefs. Academic Press, San Diego, p 96-119

Holling CS (1966) The functional response of invertebrate predators to prey density. Mem Entomol Soc Can 48: $1-86$

Horn MH (1989) Biology of marine herbivorous fishes. Oceanogr Mar Biol A Rev 27:167-246
Huffaker CB (1958) Experimental studies on predation:dispersion factors and predator-prey oscillations. Hilgardia $27: 343-383$

Ivlev VS (1961) Experimental ecology of the feeding of fishes. Yale University Press, New Haven, CT

Karr JR, Freemark KE (1985) Disturbance and vertebrates: an integrative perspective. In: Pickett STA, White PS (eds) The ecology of natural disturbance and patch dynamics. Academic Press, Orlando, p 153-168 
Keough MJ (1984) Effects of patch size on the abundance of sessile marine invertebrates. Ecology 65:423-437

Knowlton $N$ (1992) Thresholds and multiple stable states in coral reef community dynamics. Am Zool 32:674-682

Knowlton N, Lang JC, Keller BD (1990) Case study of natural population collapse: post-hurricane predation on Jamaican staghorn corals. Smithson Contrib Mar Sci 31 $1-25$

Lang C, Mann KH (1976) Changes in sea urchin populations after the destruction of kelp beds. Mar Biol 36: $321-326$

Laur DR (1990) The differential effects of macroinvertebrates and fish on 'turf' communities. Dissertation, Univ of California, Santa Barbara

Lawrence JM (1975) On the relationships between marine plants and sea urchins. Oceanogr Mar Biol 13:213-286

Mann KH (1982) Kelp, sea urchins and predators: a review of strong interactions in rocky subtidal systems of eastern Canada, 1970-1980. Neth J Sea Res 16:414-423

McLaughlin JF, Roughgarden J (1993) Species interactions in space. In: Rickleffs RR. Schluter D (eds) Species diversity in ecological communities. Univ Chicago Press, Chicago, p $89-98$

Menge BA, Farrell TM (1989) Community structure and interaction webs in shallow marine hard-bottom communities: tests of an environmental stress model. Adv Ecol Res 19: $189-262$

Menge BA, Sutherland JP (1987) Community regulation: variation in disturbance, competition, and predation in relation to gradients of environmental stress and recruitment. Am Nat 130:730-757

Noy-Meir I (1975) Stability of grazing systems: an applicatıon of predator-prey graphs. J Ecol 63:459-481

Oliver CD, Stephens EP (1977) Reconstruction of a mixed-species forest in central New England. Ecology 58:562-572

Osman RW, Whitlatch RB, Malatesta RJ (1992) Potential role of micro-predators in determining recruitment into a marine community. Mar Ecol Prog Ser 83:35-43

Paine RT, Levin SA (1981) Intertidal landscapes: disturbance and the dynamics of pattern. Ecol Monogr 51:145-178

Paine RT, Vadas RL (1969) The effect of grazing by sea urchins, Strongylocentrotus spp., on benthic algal populations. Limnol Oceanogr 14:710-719

Pearse JS, Clark ME, Leighton DL, Mitchell CT, North WJ (1970) Marine waste disposal and sea urchin ecology. Ann

This article was presented by K. L. Heck, Jr (Senior Edıtorial Advisor), Dauphin Island, Alabama, USA
Rep, Kelp Habitat Improvement Project 1969-1970. Cal.f Inst Tech, Pasadena

Pearse JS, Pearse VB, Davis KK (1986) Photoperiodic regulation of gametogenesis and growth in the sea urchin Strongylocentrotus purpuratus. J Exp Zool 237:107-118

Petraitis PS, Latham RE, Niesenbaum RA (1989) The maintenance of species diversity by disturbance. $Q$ Rev Biol 64 : 393-417

Pickett STA, White PS (1985) The ecology of natural disturbance and patch dynamics. Academic Press, Orlando

Rosenzweig ML, MacArthur RH (1963) Graphic representation and stability conditions of predator-prey interactions. Am Nat 97:209-223

Rowley RJ (1990) Newly settled sea urchins in a kelp bed and urchin barren ground: a comparison of growth and mortality. Mar Ecol Prog Ser 62.229-240

Schowalter TD (1985) Adaptations of insects to disturbance. In: Pickett STA, White PS (eds) The ecology of natural disturbance and patch dynamics. Academic Press, Orlando, p 235-252

Sebens KP (1987) The ecology of indeterminate growth in animals. Ann Rev Ecol Syst 18:371-407

Sebens KP (1991) Habitat structure and community dynamics in manne benthic systems. In: Bell SS, McCoy ED, Muchinsky HR (eds) Habitat structure: the physical arrangement of objects in space. Chapman and Hall, London, p 211-234

Sih A, Crowley P, McPeek M, Petranka P, Strohmeier K (1985) Predation, competition, and prey communities: a review of field experiments. A Rev Ecol Syst 16:269-311

Sousa WP (1984) The role of disturbance in natural communities. Ann Rev Ecol Syst 15:353-391

Taylor AD (1990) Metapopulations, dispersal, and predatorprey dynamics: an overview. Ecology 71:429-436

Vadas RL (1977) Preferential feeding, an optimization strategy in sea urchins. Ecol Monogr 47:337-371

Walde SJ (1994) Immigration and the dynamics of a predatorprey interaction in biological control. J Anim Ecol 63 $337-346$

Wiens JA (1985) Vertebrate responses to environmental patchiness in arid and semi-arid ecosystems. In: Pickett STA, White PS (eds) The ecology of natural disturbance and patch dynamics. Academic Press, Orlando, p 153-168

Wooton RJ (1990) Ecology of teleost fishes. Chapman \& Hall. London

Manuscript first received: January 11, 1995

Revised version accepted: February 15, 1996 